$05.6 ; 13.3$

\title{
Аморфизация кремниевых нанонитей при облучении ионами аргона
}

\author{
(C) А.В. Кононина ${ }^{1}$, Ю.В. Балакшин ${ }^{1,2}$, К.А. Гончар ${ }^{1}$, И.В. Божьев ${ }^{1,3}$, А.А. Шемухин ${ }^{1,2}$, В.С. Черныш ${ }^{1,2}$ \\ ${ }^{1}$ Московский государственный университет им. М.В. Ломоносова, Москва, Россия \\ ${ }^{2}$ Научно-исследовательский институт ядерной фризики им. Д.В. Скобельцына Московского государственного \\ университета им. М.В. Ломоносова, Москва, Россия \\ ${ }^{3}$ Центр квантовых технологий Московского государственного университета им. М.В. Ломоносова, Москва, Россия \\ E-mail: anastasiia.kozhemyako@mail.ru
}

Поступило в Редакцию 10 августа 2021 г.

В окончательной редакции 27 сентября 2021 г.

Принято к публикации 28 сентября 2021 г.

Проведено облучение кремниевых нанонитей ионами $\mathrm{Ar}^{+}$с энергией $250 \mathrm{keV}$ и флюенсами от $10^{13}$ до $10^{16} \mathrm{~cm}^{-2}$. Методом комбинационного рассеяния света исследована зависимость степени разупорядоченности структуры под действием ионного облучения от флюенса. Показано, что аморфизация пористого кремния происходит при бо́льших значениях числа смещений на атом, чем в тонких пленках кремния.

Ключевые слова: кремниевые нанонити, комбинационное рассеяние света, дефектообразование.

DOI: 10.21883/PJTF.2022.02.51912.18989

Наноструктуры на основе кремния сегодня активно исследуются во многих областях наноэлектроники $[1,2]$. В последнее время среди кремниевых наноструктур большой интерес стали вызывать кремниевые нанонити. Чувствительные элементы, изготовленные на их основе, могут использоваться для обнаружения различных респираторных вирусов [3], на основе кремниевых нанонитей производятся высокочувствительные биосенсоры, фотоэлектрические устройства, устройства для хранения и преобразования энергии $[4,5]$.

Влияние ионного облучения на свойства и структуру кремниевых нанонитей мало изучено. Однако эффективность данного метода модификации очевидна. В работе [6] показано, что облучение ионами бора при разных углах падения пучка позволяет управлять проводимостью подложки из кремниевых нанонитей. В [7] показана возможность управления смачиваемостью кремниевых нанонитей при воздействии на мишень протонным пучком. Методом ионной имплантации в массивах кремниевых нанонитей могут создаваться $p-n$-переходы для последующей реализации на их основе функциональных устройств [8].

При рассмотрении влияния ионного облучения на свойства структур необходимо кроме внедряемых примесей также учитывать радиационно-индуцированные дефекты. Их присутствие значительно влияет на характеристики полупроводников. От концентрации дефектов зависит тепловая проводимость [9], электроннодырочный ток и условия пробоев [10], концентрация парамагнитных центров [11], спектры оптического излучения и поглощения в полупроводниковых структурах [12].

В настоящей работе исследована динамика аморфизации кремниевых нанонитей под действием облучения ионами аргона. Полученные результаты сравниваются со случаем аморфизации пористого и массивного кремния.
Массив кремниевых нанонитей (КНН) был облучен ионами $\mathrm{Ar}^{+}$с энергией $250 \mathrm{keV}$ и ионными флюенсами от $10^{13}$ до $10^{16} \mathrm{~cm}^{-2}$. При помощи метода комбинационного рассеяния света (КРС) был исследован процесс дефектообразования.

КНН были получены методом металлстимулированного химического травления (МСXТ) пластин $c$-Si $p$-типа проводимости с кристаллографической ориентацией (100) и удельным сопротивлением 10-20 $\Omega \cdot \mathrm{cm}$. В качестве металла катализатора использовалось золото, которое было удалено с помощью раствора „царской водки“ $\left(\mathrm{HCl}: \mathrm{HNO}_{3}\right)$.

Структурные свойства были изучены с использованием сканирующего электронного микроскопа (СЭМ) Carl Zeiss SUPRA 40 FE-SEM. CЭМ-изображение полученных КНН представлено на рис. 1. Как видно из рисунка, толщина слоя КНН составляла $4.5 \mu \mathrm{m}$, диаметр нанонитей был равен $10-50 \mathrm{~nm}$, а расстояние между нанонитями - 100-200 nm. Наноструктуры, получаемые

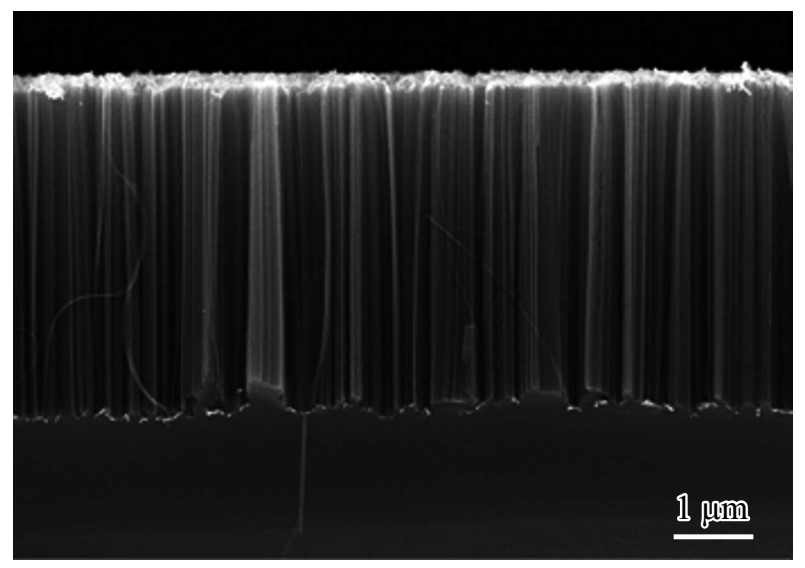

Рис. 1. СЭМ-изображение бокового среза образцов КНН, полученных методом МСXТ. 


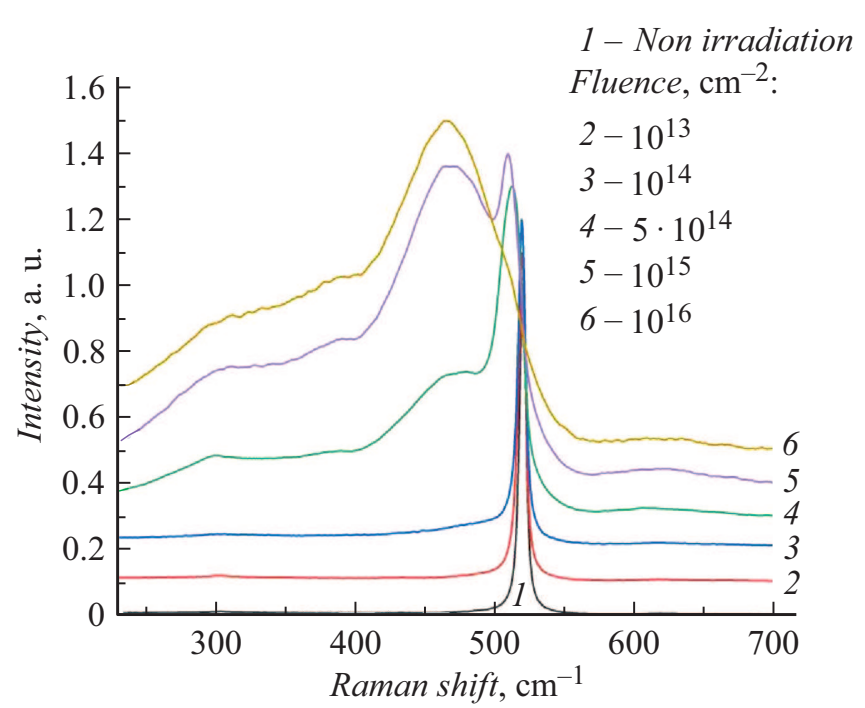

Рис. 2. Интенсивность спектра комбинационного рассеяния света, полученного от массива кремниевых нанонитей до и после облучения ионами $\mathrm{Ar}^{+}$с энергией $250 \mathrm{keV}$.

в результате травления, состоят из кристаллического остова, покрытого оксидным слоем, что подтверждено в ряде исследований $[13,14]$.

Облучение проводилось на ускорительном комплекce HVEE-500 [15]. Экспериментальная линия содержит системы фокусировки ионного пучка и сканирования мишени, а также ловушку нейтральных частиц, систему подавления вторичных электронов для контроля флюенса облучения. Облучение проводилось при комнатной температуре, рабочее давление в камере не превышало $10^{-5} \mathrm{~Pa}$, плотность тока пучка составляла $0.5 \mu \mathrm{A} / \mathrm{cm}^{2}$ и исключала нагрев образца в процессе облучения.

Спектры КРС были получены при комнатной температуре на установке „Зондовая нанолаборатория ИНТЕГРА Спектра“ с использованием лазера с длиной волны излучения $472.9 \mathrm{~nm}$, мощность лазера при измерении составляла $4.2 \mathrm{~mW} / \mathrm{cm}^{2}$.

На рис. 2 приведены спектры КРС, полученные от массива КНН до и после облучения ионами $\mathrm{Ar}^{+} \mathrm{c}$ энергией $250 \mathrm{keV}$. В спектре КРС от необлученного образца и образцов, облученных при малых флюенсах, присутствует интенсивный пик при $520 \mathrm{~cm}^{-1}$, который соответствует кристаллической фазе кремния [16]. Спектры КРС от образцов, облученных при больших ионных флюенсах, содержат широкий пик с максимумом около $460-480 \mathrm{~cm}^{-1}$, а также менее интенсивные пики при 300 и $380 \mathrm{~cm}^{-1}$. Последние два пика относятся к аморфному кремнию [17]. Широкий пик около $460-480 \mathrm{~cm}^{-1}$ может являться суперпозицией нескольких пиков, относящихся к аморфному кремнию $\left(470-480 \mathrm{~cm}^{-1}\right)[17,18]$ и аморфному диоксиду кремния (446 и $492 \mathrm{~cm}^{-1}$ ) [19]. С ростом ионного флюенса интенсивность пика, относящегося к кристаллической фазе, снижается. Пик, соответствующий фазам аморфных кремния и диоксида
Значения флюенса в единицах ion $/ \mathrm{cm}^{2}$ и dpa

\begin{tabular}{c|c}
\hline \multicolumn{2}{c}{ Флюенс } \\
\hline ion/cm $\mathrm{cm}^{2}$ & $\mathrm{dpa}$ \\
\hline $10^{16}$ & 18 \\
$10^{15}$ & 1.8 \\
$5 \cdot 10^{14}$ & 0.9 \\
$10^{14}$ & 0.18 \\
$10^{13}$ & 0.02
\end{tabular}

кремния, сначала появляется как плечо интенсивного пика при $520 \mathrm{~cm}^{-1}$, с ростом флюенса суммарная интенсивность этой группы пиков возрастает. Это указывает на разупорядочение кристаллической структуры под действием ионного пучка. В спектре, полученном от образца, облученного с наибольшим флюенсом, пик при $520 \mathrm{~cm}^{-1}$ полностью отсутствует, и спектр состоит из широкого пика с максимумом около $460-480 \mathrm{~cm}^{-1}$, что свидетельствует о полной аморфизации структуры.

Для сравнения полученных для КНН результатов с данными для других кремниевых структур параметры имплантации были переведены в универсальные единицы dpa [20] (см. таблицу). С учетом структурных особенностей массива нанонитей и геометрии эксперимента расчет параметра dра (числа смещений на атом) был проведен по алгоритму, соответствующему объемному кремнию [21].

Отметим, что при двух наименьших флюенсах облучения (0.02 и $0.18 \mathrm{dpa)}$ максимум пика, относящегося к кристаллической фазе кремния, сохраняет свое положение и остается при $520 \mathrm{~cm}^{-1}$. При флюенсе $5 \cdot 10^{14} \mathrm{~cm}^{-2}$ (0.9 dpa) данный пик сдвигается в область меньших волновых чисел на $\Delta \omega=8 \mathrm{~cm}^{-1}$, и его максимум находится при $512 \mathrm{~cm}^{-1}$. С дальнейшим ростом флюенса величина сдвига $\Delta \omega$ продолжает увеличиваться, при флюенсе $10^{15} \mathrm{~cm}^{-2}$ максимум данного пика находится при $509 \mathrm{~cm}^{-1}$, что соответствует сдвигу $\Delta \omega=11 \mathrm{~cm}^{-1}$ (рис. 3).

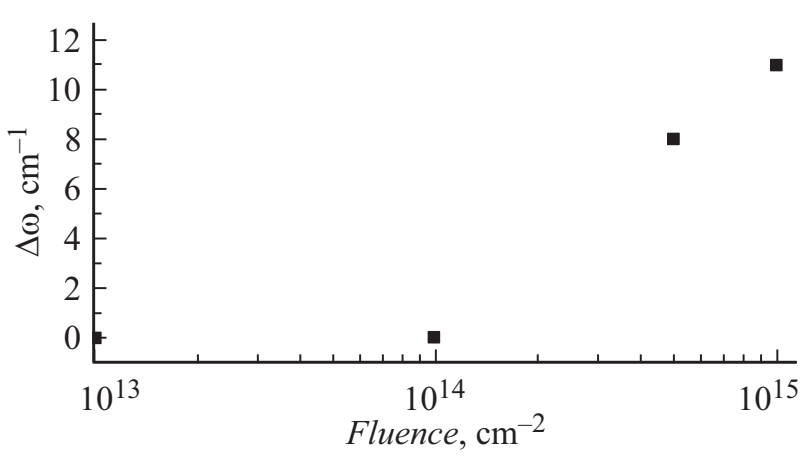

Рис. 3. Зависимость величины сдвига пика КРС, соответствующего кристаллической фазе кремния, от величины ионного флюенса. 
Смещение пика, соответствующего сигналу от кристаллической фазы кремния, может указывать на проявление квантово-размерного эффекта, в частности на появление пространственного ограничения фононов в наноструктурированных материалах из-за присутствия в структуре наночастиц с размерами менее $10 \mathrm{~nm}$, а увеличение сдвига с ростом флюенса облучения может свидетельствовать об уменьшении размера этих наночастиц $[22,23]$. Полученные результаты согласуются с результатами работы [21], где рассматривается модель, в которой при флюенсах, соответствующих величине менее $0.5 \mathrm{dpa}$, происходит накопление простейших дефектов в кристалле кремния, а далее идет объединение разрушенных областей. С ростом флюенса это приводит к формированию кристаллических неразрушенных кластеров, окруженных аморфной фазой кремния.

При значении $1.8 \mathrm{dpa}$ в спектре наряду с пиком, относящимся к аморфной фазе, присутствует явный пик, относящийся к кристаллической фазе. Однако в пленках монокристаллического кремния при близком значении $1.7 \mathrm{dpa}$ данный пик практически отсутствует [22]. При этом в спектре КРС, полученном от пористого кремния с пористостью $50 \%$, подвергнутого облучению при значении $2 \mathrm{dpa}$, также наблюдается пик при $520 \mathrm{~cm}^{-1}$ [11]. Согласно данным рис. 2 , при значении $18 \mathrm{dpa} \mathrm{с} \mathrm{помощью}$ методов КРС наблюдается полное разрушение кристаллической структуры.

В заключение отметим, что, согласно КРС, разрушение структуры нанонитей происходит при бо́льших значениях параметра dpa, чем в случае тонких пленок кремния. При этом нанонити и пористый кремний (пористость 50\%) аморфизуются при близких значениях dpa.

\section{Благодарности}

При проведении исследования использовалось оборудование Учебно-методического центра литографии и микроскопии МГУ им. М.В. Ломоносова.

\section{Финансирование работы}

Исследование выполнено при финансовой поддержке Российского фонда фундаментальных исследований в рамках научного проекта № 19-32-90174.

\section{Конфликт интересов}

Авторы заявляют, что у них нет конфликта интересов.

\section{Список литературы}

[1] R. Smerdov, Yu. Spivak, I. Bizyaev, P. Somov, V. Gerasimov, A. Mustafaev, V. Moshnikov, Electronics, 10 (1), 42 (2021). DOI: 10.3390/electronics10010042

[2] R. Castro, Y. Spivak, S. Shevchenko, V. Moshnikov, Materials, 14 (10), 2471 (2021). DOI: 10.3390/ma14102471
[3] M.B. Gongalsky, U.A. Tsurikova, J.V. Samsonova, G.Z. Gvindzhiliiia, K.A. Gonchar, N.Yu. Saushkin, A.A. Kudryavtsev, E.A. Kropotkina, A.S. Gambaryan, L.A. Osminkina, Results Mater. 6, 100084 (2020). DOI: $10.1016 /$ j.rinma.2020.100084

[4] N. Chartuprayoon, M. Zhang, W. Bosze, Y.-H. Choa, N.V. Myung, Biosens. Bioelectron., 63, 432 (2015). DOI: 10.1016/j.bios.2014.07.043

[5] А.В. Павликов, О.В. Рахимова, П.К. Кашкаров, Вестн. Моск. ун-та. Сер. 3. Физика. Астрономия, № 2, 77 (2018). [A.V. Pavlikov, O.V. Rakhimova, P.K. Kashkarov, Moscow Univ. Phys. Bull., 73 (2), 199 (2018). DOI: $10.3103 / \mathrm{S} 0027134918020121]$.

[6] S. Aziza, A. Ripp, D. Horvitz, Y. Rosenwaks, Mater. Sci. Semicond. Process., 75, 43 (2018). DOI: $10.1016 /$ j.mssp.2017.11.001

[7] V.S. Vendamani, D. Kanjilal, S. Venugopal Rao, Chem. Phys., 548, 111242 (2021). DOI: 10.1016/j.chemphys.2021.111242

[8] S. Hoffmann, J. Bauer, C. Ronning, Th. Stelzner, J. Michler, C. Ballif, V. Sivakov, S.H. Christiansen, Nano Lett, 9 (4), 1341 (2009). DOI: 10.1021/n1802977m

[9] M.G. Shahraki, Z. Zeinali, J. Phys. Chem. Solids, 85, 233 (2015). DOI: 10.1016/j.jpcs.2015.06.001

[10] А.А. Шемухин, Ю.В. Балакшин, В.С. Черныш, А.С. Патракеев, С.А. Голубков, Н.Н. Егоров, А.И. Сидоров, Б.А. Малюков, В.Н. Стаценко, В.Д. Чумак, Письма в ЖТФ, 38 (19), 83 (2012). [A.А. Shemukhin, Yu.V. Balakshin, V.S. Chernysh, A.S. Patrakeev, S.A. Golubkov, N.N. Egorov, A.I. Sidorov, B.A. Malyukov, V.N. Statsenko, V.D. Chumak, Tech. Phys. Lett., 38 (10), 907 (2012). DOI: 10.1134/S1063785012100112].

[11] A.P. Evseev, A.V. Kozhemiako, Yu.V. Kargina, Yu.V. Balakshin, E.A. Zvereva, V.S. Chernysh, M.B. Gongalsky, A.A. Shemukhin, Rad. Phys. Chem., 176, 109061 (2020). DOI: 10.1016/j.radphyschem.2020.109061

[12] S.D. Trofimov, S.A. Tarelkin, S.V. Bolshedvorskii, V.S. Bormashov, S.Yu. Troshchiev, A.V. Golovanov, N.V. Luparev, D.D. Prikhodko, K.N. Boldyrev, S.A. Terentiev, A.V. Akimov, N.I. Kargin, N.S. Kukin, A.S. Gusev, A.A. Shemukhin, Yu.V. Balakshin, S.G. Buga, V.D. Blank, Opt. Mater. Express, 10 (1), 198 (2020).

DOI: 10.1364/OME.10.000198

[13] Y.M. Spivak, A.Y. Gagarina, M.O. Portnova, A.V. Zaikina, V.A. Moshnikov, J. Phys.: Conf. Ser., 1697, 012126 (2020). DOI: 10.1088/1742-6596/1697/1/012126

[14] Yu.M. Spivak, S.V. Myakin, V.A. Moshnikov, M.F. Panov, A.O. Belorus, A.A. Bobkov, J. Nanomater., 2016, 2629582 (2016). DOI: $10.1155 / 2016 / 2629582$

[15] Ю.В. Балакшин, А.А. Шемухин, А.В. Назаров, А.В. Кожемяко, В.С. Черныш, ЖТФ, 88 (12), 1900 (2018). DOI: 10.21883/JTF.2018.12.46796.41-18 [Yu.V. Balakshin, A.A. Shemukhin, A.V. Nazarov, A.V. Kozhemiako, V.S. Chernysh, Tech. Phys., 63 (12), 1861 (2018). DOI: $10.1134 / \mathrm{S} 106378421812023 \mathrm{X}]$.

[16] Z. Sui, P.P. Leong, I.P. Herman, G.S. Higashi, H. Temkin, Appl. Phys. Lett., 60 (17), 2086 (1992). DOI: $10.1063 / 1.107097$

[17] D. Bermejo, M. Cardona, J. Non-Cryst. Solids, 32 (1-3), 405 (1979). DOI: 10.1016/0022-3093(79)90085-1 
[18] Н.Е. Маслова, А.А. Антоновский, Д.М. Жигунов, В.Ю. Тимошенко, В.Н. Глебов, В.Н. Семиногов, ФТП, 44 (8), 1074 (2010). [N.E. Maslova, A.A. Antonovsky, D.M. Zhigunov, V.Y. Timoshenko, V.N. Glebov, V.N. Seminogov, Semiconductors, 44 (8), 1040 (2010). DOI: $10.1134 / \mathrm{S} 1063782610080154]$.

[19] R.K. Biswas, P. Khan, S. Mukherjee, A.K. Mukhopadhyay, J. Ghosh, K. Muraleedharan, J. Non-Cryst. Solids, 488, 1 (2018). DOI: 10.1016/j.jnoncrysol.2018.02.037

[20] К.В. Карабешкин, П.А. Карасёв, А.И. Титов, ФТП, 47 (2), 206 (2013). [K.V. Karabeshkin, P.A. Karaseov, A.I. Titov, Semiconductors, 47 (2), 242 (2013).

DOI: $10.1134 / \mathrm{S} 1063782613020115]$.

[21] Ю.В. Балакшин, А.В. Кожемяко, А.П. Евсеев, Д.К. Миннебаев, Е.M. Elsehly, Вестн. Моск. ун-та. Сер. 3. Физика. Астрономия, № 3, 23 (2020). [Yu.V. Balakshin, A.V. Kozhemiako, A.P. Evseev, D.K. Minnebaev, E.M. Elsehly, Moscow Univ. Phys. Bull., 75 (3), 218 (2020).

DOI: 10.3103/S0027134920030030].

[22] А.В. Кожемяко, А.П. Евсеев, Ю.В. Балакшин, А.А. Шемухин, ФТП, $\mathbf{5 3}$ (6), $810 \quad$ (2019). DOI: 10.21883/FTP.2019.06.47734.9050 [A.V. Kozhemiako, A.P. Evseev, Yu.V. Balakshin, A.A. Shemukhin, Semiconductors, 53 (6), 800 (2019). DOI: $10.1134 / \mathrm{S} 1063782619060095]$.

[23] A. Colli, A. Fasoli, C. Ronning, S. Pisana, S. Piscanec, A.C. Ferrari, Nano Lett., 8 (8), 2188 (2008).

DOI: $10.1021 / \mathrm{nl} 1080610 \mathrm{~d}$ 